\title{
Clonal Immunoglobulin Heavy Chain Gene Rearrangement
}

National Cancer Institute

\section{Source}

National Cancer Institute. Clonal Immunoglobulin Heavy Chain Gene Rearrangement. NCI Thesaurus. Code C36444.

A molecular abnormality indicating rearrangement of the IGH gene in clonal populations of either lymphocytes or lymphocyte lineage neoplastic cells. 